\title{
ANÁLISE DA CONVERSAÇÃO: PANORAMA DOS ESTUDOS NO BRASIL E REPERCUSSÃO NO ENSINO ${ }^{1}$
}

\section{CONVERSATION ANALYSIS: OVERVIEW OF STUDIES IN BRAZIL AND IMPACT ON EDUCATION}

\begin{abstract}
Resumo: O trabalho apresenta uma síntese de como se instauraram os primeiros estudos sobre a conversação, a partir do trabalho do sociólogo Garfinkel - Studies in Etnomethodology - publicado em 1967. No Brasil, esses estudos se iniciam nos anos 1980, com o aparecimento dos primeiros estudos sobre a Linguística Textual e a Análise da Conversação que examinaram os elementos próprios da fala como os marcadores, o tópico, o turno. Em um segundo momento, quase concomitante, o interesse passa para a organização estrutural da conversação, numa abordagem mais especificamente linguística, procurando revelar as sistematicidades da língua. Surgem, então, as primeiras teses e dissertações e vários grupos se constituíram. O trabalho volta-se, também, para a questão do ensino da oralidade na sala de aula, com sugestão de atividades, ressaltando que os conhecimentos em torno do conceito de língua falada e língua escrita não são suficientes; é preciso que o professor disponha de subsídios em relação às especificidades dos textos que circulam em sociedade em domínios discursivos determinados.
\end{abstract}

Palavras-chave: Análise da Conversação. Oralidade e escrita. Ensino de língua portuguesa.

\begin{abstract}
The work presents a synthesis of how the first studies about conversation were established from the work of Garfinkel - Studies in Etnomethodology - published in 1967. In Brazil, these studies started in the 1980 with the first studies on Textual Linguistics and Conversation Analysis that examined elements of speech, with the markers, the topic, the shift. In a second moment, almost concomitantly, the interest shifts to the structural organization of the conversation, in a more specifically linguistic approach, seeking to reveal the systematics of the language. Then the first master's thesis and doctoral dissertations appear and several research groups are constitued.The work also focuses on the issue of teaching orality in the classroom, with suggetions of activities, emphasizing that knowledge about the concept of spoken and written language is not enough: it is necessary that the teacher has subsides in relation to the specificities of the texts that circulate in society, in determined discourse domains.
\end{abstract}

\footnotetext{
${ }^{1}$ Parte deste trabalho foi apresentada no I Encontro de Estudos do Texto em Contexto, na mesa-redonda Estudos do Texto na Atualidade, realizado na UNIFESP, em 2019, e na mesa-redonda, promovida pela Editora Parábola, intitulada A Oralidade e o Ensino de Língua, em 2020.

2 Titular de Linguística da USP (aposentada) e Titular de Língua Portuguesa da PUC-SP. Atua em: História das Ideias Linguísticas, Linguística Textual e Estudos da Oralidade, 1plfavero@uol.com.br
} 


\section{PERcursos Linguísticos • Vitória (ES) •v. 11 •n. 29 • 2021 • ISSN: 2236-2592 • Dossiê temático $\bullet O$ texto na pesquisa e no ensino: conhecimentos, práticas e desafios na contemporaneidade •}

Keywords: Conversation analysis. Orality and writing. Portuguese language teaching.

\section{Análise da Conversação}

Embora sociólogos, linguistas, antropólogos, educadores tenham se debruçado sobre o assunto e haja muitos trabalhos publicados, a concordância entre eles é pequena e ainda há muito o que fazer. A escrita tem sido vista como de estrutura complexa, formal, abstrata, enquanto a fala, de estrutura simples ou desestruturada, informal, dependente de contexto, porém os estudos sempre consideraram a fala como primária e a escrita como dela derivada. Entre nós, por exemplo, Mattoso Câmara, já em 1969, dizia: “a escrita decorre da fala e é secundária em relação a esta” (MATTOSO CÂMARA, 1969, p. 11). E Marcuschi, em 1993: "os gramáticos imaginam a fala como o lugar do erro, incorrendo no equívoco de confundir língua com a gramática codificada" (MARCUSCHI, 1993, p. 4).

\section{Como diz Biber (1988, p. 8):}

Certamente em termos de desenvolvimento urbano, a fala é o status primário. Culturalmente, os homens aprendem a falar, antes de escrever e, individualmente, as crianças aprendem a falar antes de ler e escrever. Todas as crianças aprendem a falar (excluindo-se as patologias), muitas crianças não aprendem a ler e escrever. Todas as culturas fazem uso da comunicação oral; muitas línguas são ágrafas. De uma perspectiva histórica e da teoria do desenvolvimento, a fala é claramente primária. (BIBER, 1988, p. 8).

Para os estudos sobre a língua falada, torna-se fundamental analisar como se instaura a conversação.

Há vários conceitos e posições sobre o que seja a Conversação. Há os que a conceituam, tomando-a num sentido amplo, como "o exercício prático das potencialidades cognitivas do ser humano em suas relações interpessoais." (MARCUSCHI, 1999, p. 16), englobando, assim, todo e qualquer tipo de interação, não só as conversações informais, espontâneas, sem planejamento prévio, como as formais, planejadas (debates, entrevistas, comunicações científicas etc.). Há, também, os que a consideram uma atividade, não planejada, na qual interagem dois ou mais interlocutores, que se alternam constantemente, discorrendo, constantemente, sobre temas do cotidiano. Seu desenvolvimento está ligado ao modo como a atividade interacional se organiza entre os participantes (FÁVERO, ANDRADE, AQUINO, 1999). Por conter elementos de ordem pragmática (pausas, hesitações, repetições, truncamentos, entre outros), foi considerada, até meados da década de 60 do século passado, como o lugar do caos, porém, com o surgimento dos estudos do texto, o 


\title{
PERcursos Linguísticos • Vitória (ES) •v. 11 •n. 29 • 2021 • ISSN: 2236-2592 • Dossiê temático $\bullet O$ texto na pesquisa e no ensino: conhecimentos, práticas e desafios na contemporaneidade •
}

enfoque deixa de fixar-se no produto e se desloca para o processo. Os estudos sobre ela Conversation Analysis - iniciam-se com a obra Studies in Ethnomethodology, do sóciólogo Garfinkel, publicada em 1967. O autor inicia sua obra com um capítulo intitulado $O$ que é etnometodologia? em que a conceituação de seu objeto de estudo se torna referência:

\begin{abstract}
The following studies seek to treat practical activities, practical circumstances, and practical sociological reasoning as topics of empirical study, and by paying to the most commonplace activities of daily life the attention usually accorded extraordinary events, seek to learn about them as phenomena in their own right. Their central recommendation is that the activities whereby members produce and manage settings of organized everyday affairs are identical with members the procedures for making settings "account-able". (GARFINKEL, H. 1967, p. 1)3.
\end{abstract}

A etnometodologia surgiu como uma dissidência da Sociologia, e a referida obra provocou mudanças, de "um paradigma normativo, para um paradigma interpretativo" (COULON, 1995). Sacks, Schegloff e Jefferson (1974) foram pioneiros nesses estudos, embora seu interesse não fosse linguístico, mas sociológico.

O termo designa "a metodologia usada pelos membros de uma sociedade na realização de suas atividades; é graças a essa metodologia que a realidade social e a ordem social são produzidas e que as pessoas concebem essa realidade como dada ou preestabelecida." (GULICH, 1991, p. 328-329).

Em síntese, consideram as seguintes características básicas da conversação:

- interação face a face entre pelo menos dois falantes; o número de participantes pode variar;

- ocorrência de pelo menos uma troca de falantes, e, na maioria dos casos, fala um de cada vez. O tamanho e a ordem dos turnos não são fixos;

- presença de uma sequência de ações coordenadas;

- execução num determinado tempo;

- planejamento simultâneo ou quase simultâneo à produção, sem possibilidade de apagamento.

\footnotetext{
${ }^{3}$ Os estudos a seguir buscam tratar atividades práticas, circunstâncias práticas e raciocínio sociológico prático como tópicos de estudo empírico e, ao dedicarem ás atividades mais comum do cotidiano a atenção usualmente dispensada a eventos extraordinários, procuram estudá-las como fenômenos em si. A recomendação desses estudos é a de que as atividades pelas quais os membros produzem e gerenciam situações de afazeres cotidianos organizados são idênticas aos procedimentos empregados pelos membros para tornar essas situações relatáveis. GARFINKEL, H. O que é etnometodologia? Tradução: Paulo Cortes Gago e Raul Francisco Magalhães. Revista Teoria e Cultura, Juiz de Fora, v. 4, n. 1 e 2, p. 113-134, jan./dez. 2009. Disponível em 〈https://periodicos.ufjf.br/index.php/TeoriaeCultura/article/view/12149>. Acesso em: 30 jul. 2021.
} 


\title{
PERcursos Linguísticos • Vitória (ES) •v. 11 •n. 29 • 2021 • ISSN: 2236-2592 • Dossiê temático $\bullet O$ texto na pesquisa e no ensino: conhecimentos, práticas e desafios na contemporaneidade •
}

Embora todos eles fossem sociólogos, logo atraíram a atenção dos linguistas por suas posições sobre o uso da linguagem em interação que não era caótica, no seu modo mais espontâneo e, sim, passível de análise; e isso no momento da explosão das propostas de Chomsky, que não se preocupava com os dados dos falantes em interação, mas afirmava que o falante é capaz de produzir e interpretar um número de frases bem formadas.

Porém, já em 1962, Hymes afirmava que o falante também é capaz de dominar as condições de uso adequado da língua, as possibilidades oferecidas por ela, isto é, além da competência linguística, é necessário considerar-se a competência comunicativa - conjunto de capacidades que permitem ao falante comunicar-se de modo eficaz em situações comunicativas específicas. Esses dois fatores (o fato de que, como afirmavam os sociólogos, a linguagem em interação não ser caótica, mas passível de análise e a consideração da competência comunicativa) foram responsáveis pela recepção da análise da conversação etnometodológica.

Mas, depois de algum tempo, como afirma o mesmo Coulon (ibid., p.26),

\begin{abstract}
A etnometodologia começa a cindir-se em dois grupos: o dos analistas da conversação que tentam descobrir, nas conversações, as reconstruções contextuais que lhes permitem dar um sentido e continuidade, e o dos sociólogos para os quais as fronteiras reconhecidas de sua disciplina se acham circunscritas aos objetos mais tradicionais que a sociologia estuda, como a educação, a justiça, as organizações, as administrações, a ciência. (COULON, 1995, p. 26).
\end{abstract}

No dizer de Heritage e Atkinson (1984), objetivo central das pesquisas em Análise da Conversação Etnometodológica é a descrição e explicação não da linguagem em si, mas dos métodos de ação humana, como atribuir responsabilidade, explicar-se, corrigir-se, isto é, das competências que os falantes comuns usam e de que se valem para participar de interações socialmente organizadas

Vejamos, agora, a recepção no Brasil.

\section{A Análise da Conversação no Brasil}

A década de 80 do século passado foi especialmente frutífera para a Linguística no Brasil, pois surgem os primeiros trabalhos sobre a Linguística Textual e a Análise da Conversação. O primeiro trabalho, sobre a Linguística Textual, de que se tem notícia é o do Professor Ignácio Antônio Neis da PUCRS, intitulado Por uma gramática textual, publicado na revista Letras de Hoje, revista do curso de Pós-Graduação em Linguística e Letras do Centro de Estudos Portugueses da PUCRS, em junho de 1981, no. 44. Seguem-se, em 1983, 


\section{PERcursos Linguísticos • Vitória (ES) •v. 11 •n. 29 • 2021 • ISSN: 2236-2592 • Dossiê temático $\bullet O$ texto na pesquisa e no ensino: conhecimentos, práticas e desafios na contemporaneidade •}

duas obras Linguística de texto - o que é e como se faz, de Luiz Antônio Marcuschi, publicado pela Revista do Mestrado em Letras da Universidade Federal de Pernambuco, série Debates e Lingüística textual - introdução, de Leonor Lopes Fávero e Ingedore V. Koch, publicado em São Paulo, pela Editora Cortez.

Surgem, então, as primeiras teses e dissertações que estudaram os elementos próprios da fala, como os marcadores conversacionais, dissertações de Maria Lúcia Oliveira Andrade em 1990, de Luiz Antônio da Silva e de Margareth M. Rosa, também em 1990, o tópico, dissertação de Zilda Aquino, em 1991, estudos sobre interrupções, hesitações, bem como aqueles voltados para os processos de construção do texto falado - repetição (Marcuschi), hesitação (Marcuschi), paráfrase (tese de José Gaston Hilgert, em 1989), correção (Fávero, Andrade e Aquino), perguntas e respostas (Fávero, Andrade e Aquino) e daí para o estudo dos gêneros orais (entrevistas, linguagem radiofônica, debates na televisão), semelhanças e diferenças e o meio social em que são produzidos, estabelecendo-se um diálogo com a Antropologia, Sociologia, Psicologia social e outras disciplinas focadas na interação do homem na sociedade. (Marcuschi, Paulo Galembeck, Kazuê M. de Barros, Dino Preti, Clélia Jubran, Mercedes Risso, Ingedore Koch, Gaston Hilgert, Hudinilson Urbano, Leonor L. Fávero e outros).

E a Análise da Conversação no Brasil foi caminhando por trilhas próprias, isto é, foi adquirindo sua identidade.

Quero ressaltar que, além dessas análises com objetivo de descrição linguística do "texto falado", houve e há ainda hoje, também, análises com a finalidade de discutir a passagem da oralidade para a escrita, "questão crucial para uma sociedade como a nossa, em que se precisa entender a passagem da oralidade para o letramento pleno a fim de acelerar o processo para as populações ainda alijadas até os dias de hoje da escrita e dos discursos que se organizam a partir dela" (GARCEZ, 2008, p. 21).

Essas linhas ainda se mantêm devendo-se ressaltar o diálogo com a Linguística Textual, inserindo a Análise da Conversação num quadro teórico mais amplo de estudo do texto. No decorrer desses anos, diversos grupos de estudos se constituíram. Cito alguns:

- NELFE, em 1991, na UFPE;

- Projeto da Gramática do Português Falado, coordenado pelo Professor Ataliba de Castilho, em 1988 - Grupo de Organização Textual Interativa, que, num primeiro momento discutiu a categoria de tópico discursivo, noção fundamentada na relação de interdependência entre turnos, promovida pelo movimento de entrosamento entre os interlocutores. O tópico é 


\section{PERcursos Linguísticos • Vitória (ES) •v. 11 •n. 29 • 2021 • ISSN: 2236-2592 • Dossiê temático $\bullet O$ texto na pesquisa e no ensino: conhecimentos, práticas e desafios na contemporaneidade •}

um processo essencial na organização textual-interativa da conversação (Maria Lúcia Andrade, Zilda Aquino e eu, elaboramos dois textos: correção e perguntas e respostas). Membros: Marcuschi, Clélia Jubran, Mercedes Risso, M. Cecília Souza e Silva, Mercedes Crescitelli, Ingedore Koch, Gaston Hilgert, Leonor L. Fávero com Maria Lúcia da Cunha V. Oliveira Andrade e Zilda Gaspar de O. Aquino;

- o projeto NURC, em Salvador, Recife, Rio, Porto Alegre e, principalmente em São Paulo, coordenado pelo Professor Dino Preti, que publicou regularmente as produções resultantes das pesquisas de seus membros que se utilizaram do corpus gravado na década de 70: elocuções formais, diálogo entre dois informantes e diálogo informante-entrevistador e que passaram, também, a abordar questões de oralidade em textos falados e escritos;

- na UFRJ - PEUL: Programa de estudo sobre o uso da língua;

- em Salvador;

- em Porto Alegre.

E hoje?

As questões aqui levantadas, relacionadas a uma microanálise, continuam sendo estudadas hoje, porém privilegiam-se questões relacionadas a uma macroanálise, como os gêneros orais (entrevistas, talk-shows, debates) interação em contextos policiais, interação na saúde (médico-paciente) e o grande tema: a cortesia. Congressos foram realizados sobre esse tema com êxito na Universidade Aberta de Lisboa e aqui no Brasil, havendo uma excelente bibliografia no exterior de autores como Briz, na U. de Valencia, Catherine KerbratOrecchioni da U. de Lyon, Diana Bravo, Penélope Brown e Stephen Levinson, Maria Victoria Escandell-Vidal e muitos outros.

\section{Novas perspectivas para o ensino}

Para tratar da oralidade em sala de aula, os conhecimentos em torno do conceito de língua falada e de língua escrita não são suficientes; é preciso que o professor disponha de subsídios em relação às especificidades dos textos que circulam na sociedade em domínios discursivos determinados, como o jornalístico, o acadêmico, o religioso, o jurídico etc., para que reconheça como se instaura seu processo de produção e de qual (ou quais) unidade(s) de análise se pode fazer uso para um estudo efetivo (FÁVERO; ANDRADE; AQUINO, 1999 e 2011).

Os PCN's de Língua Portuguesa (1998) abrem um espaço ainda pequeno para a inclusão de questões de oralidade em sala de aula; entretanto, poucos são os trabalhos que 


\section{PERcursos Linguísticos • Vitória (ES) •v. 11 •n. 29 • 2021 • ISSN: 2236-2592 • Dossiê temático $\bullet O$ texto na pesquisa e no ensino: conhecimentos, práticas e desafios na contemporaneidade •}

apresentam uma discussão quanto à aplicação ao ensino, como o fizeram Castilho (1998), Fávero (2005), Fávero, Andrade e Aquino (1999 e 2011), Marcuschi (2001), entre outros.

Apresento agora sugestões de atividades entre as quais se destacam: gravação de narrativa produzida por alunos (do ensino fundamental, médio e superior), transcrição e retextualização imediata para a modalidade escrita pelos mesmos alunos, mantendo o mesmo tópico, quando o aluno observará:

- eliminação de marcas estritamente interacionais, como marcadores, hesitações, truncamentos;

- inclusão da pontuação;

- substituição dos turnos por parágrafos;

- seleção lexical e estruturação sintática diferentes (por exemplo palavras mais longas no texto escrito).

Insisto em quão produtivo pode ser o processo. Inclusive em termos de utilização do texto pelo próprio aluno, nos diferentes níveis de escolaridade.

Nessa linha de trabalho, destaco, do discurso jornalístico, a análise, por exemplo, das manchetes e da linha fina (linha que surge logo abaixo da manchete e que contém a síntese da notícia).

Como já sugeriram Fávero, Andrade e Aquino (2011), o professor pode iniciar essa atividade lendo as manchetes das principais revistas de circulação nacional (como Veja, Isto é, Época etc.) ou de jornais ( $O$ Globo, Folha de S. Paulo, O Estado de S. Paulo etc.). Em seguida, pode mostrar como esses textos se estruturam, quais são suas especificidades, qual a variante linguística empregada, qual o efeito de sentido obtido com as escolhas lexicais feitas pelo enunciador:

- manchetes que relembram total ou parcialmente títulos de filmes ou de novelas:

- Merlís paulistanos: como o famoso personagem catalão da série Netflix, professores encantam alunos com metodologias e talentos... (Veja, 16/10/19).

- Os novos Merlís: professores criam métodos de ensino a distância originais para além dos aplicativos... (Veja, 15/07/20).

- O dono do pedaço : principal liderança de Paraisópolis quer transformar favela em polo de negócios (Veja, 18/09/19).

- Brasil, mostra tua cara (Correio Brasiliense, 17/04/06). 


\section{PERcursos Linguísticos • Vitória (ES) •v. 11 •n. 29 • 2021 • ISSN: 2236-2592 • Dossiê temático $\bullet O$ texto na pesquisa e no ensino: conhecimentos, práticas e desafios na contemporaneidade •}

- manchetes que retomam provérbios ou a Bíblia:

- Amar a si mesma (Claudia, outubro/18).

- A multiplicação dos santos: com o número recorde de canonizações, incluindo a da freira baiana irmã Dulce, a Igreja Católica tenta recuperar o rebanho perdido (Veja, 16/10/19).

- manchetes em que se empregam norma popular, gíria ou vocábulos em língua estrangeira:

- Bye-bye Curitiba (Veja,16/10/19)

- manchetes que retomam falas de autoridades:

- A boiada é aqui (Veja, 28/10/20).

É possível localizar na escrita textos com grande aproximação da oralidade, como ocorre na notícia a seguir (citada em Fávero, Andrade e Aquino, 2011) em que o enunciador parece dialogar com o leitor ao apresentar uma narrativa envolvente. Ao proceder à citação da voz de um dos envolvidos ("O avião não aterrissou, ele praticamente caiu no chão"), traz vivacidade ao texto, além de se responsabilizar o outro pela veracidade dos fatos. Observe-se, ainda, a diferença entre a seleção lexical empregada pelo enunciador (chocou-se contra o solo) e pela testemunha (caiu praticamente no chão) na narrativa do fato:

No momento do pouso, o aparelho chocou-se violentamente contra o solo, arremessando seus 36 passageiros ao solo .[...] "o avião não aterrissou, ele praticamente caiu no chão", contou a Veja um dos 36 passageiros a bordo (Veja, 6 jan.,1999 ,p.68. In: FÁVERO, ANDRADE e AQUINO, 2011).

Podem ser realizadas atividades escritas, utilizando-se os mesmos temas tratados durante as análises dessas notícias e manchetes, com o objetivo de estudar com o texto escrito se organiza.

Outra possibilidade, levantada também por Fávero, Andrade e Aquino (op.cit.), é tentar elaborar com os alunos um jornal falado, abordando temas (manchetes e notícias) de interesse da comunidade escolar. É produtivo observar como são adaptadas as notícias encontradas no jornal impresso para serem enunciadas em um jornal de rádio ou televisão.

Há, ainda, a questão do texto literário escrito, no caso, aqui, a crônica. 


\section{PERcursos Linguísticos • Vitória (ES) •v. 11 •n. 29 • 2021 • ISSN: 2236-2592 • Dossiê temático $\bullet O$ texto na pesquisa e no ensino: conhecimentos, práticas e desafios na contemporaneidade •}

É comum dizer-se que a crônica é um gênero híbrido que oscila entre a subjetividade da literatura e a objetividade do jornalismo, resultado da visão pessoal, subjetiva do cronista ante um fato qualquer, mas, diferentemente do repórter, o fato é para ele um meio e não um fim.

Não basta constatar a transposição da estrutura da conversação cotidiana, gênero primário (Cf. BAKHTIN, 1979), para o interior da crônica literária, gênero literário, para explicar a relação entre elas. Nela há a opção pelo coloquialismo que atrai o leitor, com a intenção de divertir, informar, ilustrar, utilizando-se de uma linguagem direcionada aos leitores apressados do jornal, veículo de informação diária, e cuja elaboração tem como característica primordial a urgência, pois “os acontecimentos são extremamente rápidos e o cronista precisa de um ritmo ágil para poder acompanhá-los Por isso sua sintaxe lembra alguma coisa desestruturada, solta, mais próxima da conversa entre dois amigos do que propriamente do texto escrito" (SÁ, 2002, p. 10-11).

Isso se observa tanto em crônicas do início do século passado, como nas de Lima Barreto e João do Rio, como nas atuais, recentes de Luís Fernando Veríssimo e de Humberto Werneck, nascidas hoje para saírem nos jornais ainda hoje, revelando seu vínculo com a história.

Na sala de aula, o trabalho com a crônica será extremamente produtivo, os índices de oralidade poderão ser explicitados, tanto os verbais como os não verbais que envolvem a conversação, por ela simulada e que vão constituindo sua textualidade. Poderão ser examinados, por exemplo, quanto à organização global, os tópicos e subtópicos, a organização dos diálogos (simétricos e assimétricos) e os pares adjacentes, elemento básico da interação.

Devem ser observadas também não só as marcas da oralidade, mas também as da modalidade escrita, fortemente presentes, como a estruturação dos parágrafos, a transição de um para outro etc., o que se deve ao óbvio - mesmo simulando a fala, a crônica não deixa de ser um gênero escrito.

\section{Conclusão}

Como se pode ver no decorrer do trabalho não se pode pensar a língua falada e a língua escrita como modalidades invariantes. Como já afirmava Berruto, em 1985, no interior dessas modalidades, há variações provocadas pelas condições de produção e pelo uso. 


\section{PERcursos Linguísticos • Vitória (ES) •v. 11 •n. 29 • 2021 • ISSN: 2236-2592 • Dossiê temático $\bullet O$ texto na pesquisa e no ensino: conhecimentos, práticas e desafios na contemporaneidade •}

Conforme já apontaram Fávero, Andrade e Aquino (2011), "há uma tendência hoje em dia para que a oralidade se apresente de modo constante no discurso escrito e esta é uma maneira eficiente de se construir um texto mais envolvente para o leitor como observamos no discurso jornalístico que traduz, no uso da marcas de oralidade na escrita, sua manifestação de criatividade e de modernidade, buscando influenciar o leitor e criar efeitos de sentido pretendidos" (FÁVERO, ANDRADE, AQUINO, 2011, p. 27).

\section{Referências}

BAKHTIN, M. (VOLOSHINOV). Marxismo e filosofia da linguagem. Trad. M. Lahud e Yara F. Vieira. São Paulo: Hucitec, 1979.

BERRUTO, G. Z. Per una caratterizzazione del parlato: l'italiano parlato ha un'altra grammatica? In: Holtus, G.; RADTKE, E. (Orgs). Gesprochenes Italienisch in Geschichte und Gegenwart. Tübingen: Narr, 1985, p. 120-153.

BIBER, D. Variation across speech and writing. Cambridge, UK: Cambridge University Press, 1988.

BRASIL. Parâmetros Curriculares Nacionais: Língua Portuguesa. Brasília: MEC/SEF, 1998.

CASTILHO, A. T. A língua falada no ensino de português. São Paulo: Contexto, 1998.

COULON, A. Etnometodologia. Petrópolis, Vozes, 1995.

FÁvero, L. L. Coesão e coerência no texto conversacional. In: Coesão e coerência textuais. 10. ed. revista e atualizada. São Paulo: Ática, 2005, p.84-99.

FÁVERO, L. L.; ANDRADE, M. L. C. V. O.; AQUINO, Z. G. O. Estratégias de construção do texto falado: a correção. In: KATO, M. A. (Org.) Gramática do português falado. v. 5. São Paulo: Humanitas/FFLCH/USP; Campinas: Editora da Unicamp, 1996, p. 355-366.

FÁVERO, L. L.; ANDRADE, M. L. C. V. O.; AQUINO, Z. G. O. O par dialógico perguntaresposta. In: JUBRAN, C. C. A. S; KOCH, I. G. V. Gramática do português culto falado no Brasil. v. 1, Construção do texto falado. Campinas: UNICAMP, 2006, p. 133-166.

FÁVERO, L. L; ANDRADE, M. L. C. V. O.; Aquino, Z. G. O. Oralidade e escrita: perspectivas para o ensino de ensino de língua materna. São Paulo: Cortez, 1999.

Reflexões sobre oralidade e escrita no ensino de Língua Portuguesa. In:

ELIAS, V. M. da S. (Org.). Ensino de língua portuguesa: oralidade, escrita e leitura. São Paulo, Contexto, 2011, p. 13-28.

GARCEZ, P. M. A perspectiva da Análise da Conversa Etnometodológica sobre o uso da linguagem em interação social. In: LODER, L.; JUNG, N. M. (Orgs.). Fala-em-interação social: uma introdução à Análise da Conversa Etnometodológica. Campinas, Mercado de Letras, 2008, p. 17-38. 


\section{PERcursos Linguísticos • Vitória (ES) •v. 11 •n. 29 • 2021 • ISSN: 2236-2592 • Dossiê temático $\bullet O$ texto na pesquisa e no ensino: conhecimentos, práticas e desafios na contemporaneidade •}

GARFINKEL, H. What is ethnomethodology? In: GARFINKEL, H. Studies in Ethnomethodology. Englewood Cliffs; New Jersey: Prentice-Hall, 1996 [1967], p. 1-34.

GULICH, E. Pour une ethnométhodologie linguistique: description des séquences conversationelles explicatives. In: DAUSENDSCHÖN-GAY, U. (Ed.). Linguistische Interaktionsanalysen. Tubigen: Niemeyer, 1991, p. 325-364.

HERITAGE, J.; ATKINSON, J. M. Introduction. In: ATKINSON, J. M.; HERITAGE, J. Structures of Social Action. Cambridge: Cambridge University Press, 1984, p. 1-15.

HYMES, D. The Ethnography of Speaking. In: GLADWIN, T.; STURTEVANT, W. (Eds.). Anthropology and Human Behavior. Washington: American Anthropology Association, 1962, p. 13-53.

MARCUSCHI, L. A. O tratamento da oralidade no ensino de língua. Universidade Federal de Pernambuco. Recife. Texto mimeografado, 1993.

Marcas de interatividade no processo de textualização da escrita. In: RODRIGUES, Â. C. S.; ALVES, I. M.; GOLDSTEIN, N. S. (Orgs.). I Seminário de Filologia e Língua Portuguesa. São Paulo: Humanitas, 1999, p.139-156.

. Da fala para a escrita: o tratamento da oralidade no ensino de língua. São Paulo: Cortez, 2001.

MATTOSO CÂMARA, J. Problemas de Lingüística descritiva. Petrópolis: Vozes, 1969.

SÁ, J. A crônica. 3. ed. São Paulo: Ática, 2002.

SACKS, H., SCHEGLOFF, E. \& JEFFERSON, G. A simplest systematics for the organization of turn-talking for conversation. Language, 50, 1974. 